\title{
Visual Responses of Neurons in the Nucleus of the Basal Optic Root to Stationary Stimuli in Pigeons
}

\author{
Yong Gu, Yuan Wang, and Shu-Rong Wang ${ }^{\star}$ \\ Laboratory for Visual Information Processing, Center for Brain and Cognitive Sciences, Institute of Biophysics, \\ Chinese Academy of Sciences, Beijing, China
}

The nucleus of the basal optic root of the accessory optic system in pigeons is involved in generating optokinetic nystagmus, which stabilizes object images on the retina by compensatory eye movements. Previous studies have indicated that basal optic neurons are selective for the direction and velocity of motion. The present study shows that these optokinetic cells also respond to stationary stimuli and thereby could be categorized into three groups. The first group of cells $(69.1 \%)$ responds to stationary gratings orthogonal to the preferred direction but not to gratings parallel to the preferred direction. They do not respond to stationary random-dot patterns without any orientational cues. The second group of cells $(7.4 \%)$ almost equally discharges a series of bursts in response to stationary gratings with any orientations and to random-dot patterns as well. The third group of cells $(23.5 \%)$ is responsive to motion but not to stationary gratings and random-dot patterns. The receptive field of basal optic cells is composed of an excitatory field and an inhibitory field, both of which overlap or occupy different regions in the visual field. The aforementioned properties may be attributed to the excitatory receptive field, whereas the inhibitory receptive field is functional when visual stimuli are moving in the direction opposite to the preferred direction of basal optic cells. The functional significance of visual responses of optokinetic neurons to stationary patterns is discussed.

(c) 2002 Wiley-Liss, Inc.

Key words: accessory optic system; optokinetic nystagmus; orientation selectivity; receptive field

The nucleus of the basal optic root (nBOR) of the accessory optic system in birds is thought to be homologous to the terminal nuclei of the accessory optic tract in mammals (Fite, 1985; McKenna and Wallman, 1985). These nuclei are involved in generating optokinetic nystagmus, which stabilizes object images on the retina by compensatory eye movements. In addition to its coordination and competition in generating optokinetic nystagmus with the pretectal nucleus lentiformis mesencephali (Baldo and Britto, 1990; Nogueira and Britto, 1991; Gu et al., 2001; Wang et al., 2001), nBOR also exerts modulatory actions on rotundal neurons in the tectofugal pathway

(C) 2002 Wiley-Liss, Inc.
(Wang et al., 2000a; Diekamp et al., 2001) and on visual cells in the dorsolateral thalamus $(\mathrm{Gu}$, Cao, and Wang, unpublished data) in the thalamofugal pathway in pigeons.

Electrophysiological studies have shown that visual neurons within the avian nBOR (Britto et al., 1981; Burns and Wallman, 1981; Morgan and Frost, 1981; Gioanni et al., 1984; Wylie and Frost, 1990; Wolf-Oberhollenzer and Kirschfeld, 1994; Zhang et al., 1999) and its mammalian homologues (Soodak and Simpson, 1988; Mustari and Fuchs, 1989) respond to motion of large-field stimuli in particular (preferred) directions. They usually prefer motion in the ventrodorsal, dorsoventral, or nasotemporal directions. The nBOR neurons also respond in an inhibitory manner to motion in the direction opposite to the preferred direction (Morgan and Frost, 1981; Britto et al., 1990; Frost and Sun, 1997; Zhang et al., 1999).

All these physiological studies on nBOR cells used moving targets as visual stimuli to describe the directional preference and velocity selectivity of optokinetic cells. A recent study has shown that visual cells in the pigeon $\mathrm{nBOR}$ respond vigorously to motion of a leading edge, whose orientation is an essential factor affecting visual responses of these cells (Wang et al., 2000b). We therefore wondered whether optokinetic neurons respond to stationary objects and what the relationship between the preferred direction and the orientation of visual stimuli would be in the pigeon nBOR. The present study was undertaken by using extracellular recording and quantitative analysis techniques.

\section{MATERIALS AND METHODS}

Twenty-two adult pigeons (Columba livia) of either sex, weighing 360-430 g, were used following the policy on the use of animals in neuroscience research approved by the Society for

Contract grant sponsor: National Natural Science Foundation of China; Contract grant sponsor: Chinese Academy of Sciences.

*Correspondence to: Shu-Rong Wang, Laboratory for Visual Information Processing, Institute of Biophysics, Chinese Academy of Sciences, 15 Datun Road, Beijing 100101, China.

E-mail: wangsr@sun5.ibp.ac.cn or srwang@hotmail.com

Received 22 June 2001; Revised 13 November 2001; Accepted 16 November 2001 
Neuroscience. Each pigeon was anesthetized with urethane $(20 \%, 1 \mathrm{ml} / 100 \mathrm{~g})$ and then placed in a stereotaxic apparatus. The left caudal forebrain was surgically exposed and the dura mater overlying nBOR excised. The right eye was kept open, the left covered. The eye movements were intermittently monitored by the experimenter, and no observable movements were found. Isolation of units unresponsive to stationary patterns also gave some indication of the eye stability. A screen of $130^{\circ}$ vertical $\times 140^{\circ}$ horizontal was positioned $40 \mathrm{~cm}$ from the right eye. The horizontal meridian of the visual field was rotated clockwise by $38^{\circ}$ to meet the pigeon's normal conditions (Erichsen et al., 1989). Gratings consisting of equal-width blackand-white stripes (0.02-0.5 cycles per degree of visual angle) or random-dot patterns (1-12 degree dot size, 0.44-64 dots/100 square degrees in density) as visual stimuli were generated by a workstation (Silicon Graphics Indigo 2) and back-projected with a three-color projector (Electrohome ECP4). This projector could automatically focus over the whole screen so that the out-of-focus blur at any points on the screen was eliminated. It showed a blank white or black field on the screen to test ON-OFF responses. The luminance of blackness and whiteness in visual stimuli was 0.1 and 6.6 candles per degree $/ \mathrm{m}^{2}$, respectively, so the black-white contrast was 0.97 . The gratings were projected onto the screen stationary, with orientation parallel $\left(0^{\circ}\right)$, orthogonal $\left(90^{\circ}\right)$, or $45^{\circ}$ or $135^{\circ}$ oblique to the preferred direction of a given cell. In some cases, effects of the spatial frequency of gratings on visual responses were examined, but the spatial phase dependence was not studied here. The randomdot patterns without orientational cues were also presented to examine visual responses of the cell to stationary stimuli. Stimuli of different types (stationary gratings, moving gratings, randomdot patterns) were presented in blocks of interleaved trials, and the order of stimuli (of various orientations, spatial frequencies, and/or types) was randomized. The interval between consecutive stimulations was at least $5 \mathrm{sec}$ to ensure that the cell completely recovered. The stimuli stayed on the screen for 5-300 sec, but the number of spikes was usually collected in the first 1.5-2.5 sec after stimulus presentation, and an average firing rate in three sweeps was calculated. Statistical analyses were made between the control and the experimental values obtained with various gratings and dot patterns.

Visual cells were stereotaxically recorded from $\mathrm{nBOR}$ according to the pigeon brain atlas (Karten and Hodos, 1967) with a micropipette (2-3 $\mu \mathrm{m}$ tip diameter) filled with $2 \mathrm{M}$ sodium acetate and $2 \%$ pontamine-sky blue (Hellon et al., 1971). Neuronal spikes were amplified, displayed on an oscilloscope, and fed into the workstation computer for online analysis. The location and extent of the excitatory receptive field (ERF) of a given cell were mapped with the workstation (Fu et al., 1998a; Zhang et al., 1999). In some cases, the inhibitory receptive field (IRF) was also mapped. A random-dot pattern consisting of dots of $2^{\circ}$ visual angle in size and 1.4 dots $/ 100$ square degrees in density was moved at $8^{\circ} / \mathrm{sec}$ over the receptive field randomly in eight directions [spaced by $45^{\circ}$ relative to nasal $\left(0^{\circ}\right)$ ] to determine the preferred direction of the cell. The orientation of gratings was always specified relative to the preferred direction of the cell. When ERF and/or IRF were examined, a display window technique was used to restrict stimulation within these particular regions.
At the end of some experiments, the recording sites of visual neurons were marked with pontamine-sky blue applied by negative current pulses of $10-20 \mu \mathrm{A}$ in intensity and $0.5 \mathrm{sec}$ in duration at $1 \mathrm{~Hz}$ for $10-15 \mathrm{~min}$. With the animal under deep anesthesia, the brain was removed from the skull, fixed in $4 \%$ paraformaldehyde for 6-12 hr and soaked in 30\% sucrose solution in a refrigerator overnight. Frozen sections were cut at 100 $\mu \mathrm{m}$ thickness and counterstained with neutral red. Sections were dehydrated and covered for subsequent microscopic observation.

\section{RESULTS}

Sixty-eight nBOR neurons were recorded, and their orientation sensitivity to stationary stimuli was examined. They included 67 directional cells preferring motion in a particular (preferred) direction and 1 omnidirectional cell responding almost equally to motion in all directions examined. Among these, 51 cells (75\%) were spontaneously firing at rates ranging from 3 to 51 spikes/sec, and 17 others $(25 \%)$ were silent. According to their orientation selectivity, these cells could be categorized into three groups.

The first group included 47 cells (69.1\%) that were sensitive to orientation of gratings (Fig. 1A). They contained 35 spontaneous cells and 12 silent cells. They produced ON-OFF (4 cells), OFF (25 cells), or no (18 cells) responses to light on and off. The spontaneous cells had an average spontaneous rate of $16.0 \pm 11.3$ spikes $/ \mathrm{sec}$ (mean $\pm \mathrm{SD}, \mathrm{n}=35$ ) and responded to stationary gratings orthogonal to the preferred direction with a firing rate of $46.7 \pm 23.2$ spikes/sec, showing obvious visual responses. On the other hand, these cells fired at a rate of $16.2 \pm 11.8$ spikes/sec to stationary gratings parallel to the preferred direction, clearly showing that the rate was not different from the spontaneous rate. Gratings that were $45^{\circ}$ or $135^{\circ}$ oblique to the preferred direction elicited intermediate responses in 18 cells examined. These cells had a spontaneous rate of $14.2 \pm 8.3 \mathrm{spikes} / \mathrm{sec}$ and responded to $45^{\circ}$ gratings with a higher rate of $22.9 \pm 12.8 \mathrm{spikes} / \mathrm{sec}(t=$ $5.756, \mathrm{n}=18, P<0.01)$ and to $135^{\circ}$ gratings with a higher rate of $22.2 \pm 10.7$ spikes $/ \mathrm{sec}(t=6.394, \mathrm{n}=18$, $P<0.01)$. In contrast, all 26 cells examined did not respond to stationary random-dot patterns without any orientational cues. They had a spontaneous rate of $13.3 \pm$ 7.6 spikes/sec and responded to random-dot patterns with a firing rate of $14.5 \pm 8.9$ spikes/sec, showing no significant change $(t=1.699, \mathrm{n}=26, P>0.01)$. This orientation selectivity was also true for 12 silent cells (spontaneous rate $=0)$. They discharged visual firings at $28.9 \pm$ $16.7,8.0 \pm 7.0$, and $8.6 \pm 7.6$ spikes/sec, respectively, in response to stationary gratings orthogonal, $45^{\circ}$, and $135^{\circ}$ to the preferred direction. They did not respond to gratings parallel to the preferred direction or to random-dot patterns at all. The spatial frequency of gratings is also a factor affecting visual responsiveness of $\mathrm{nBOR}$ cells. Among 16 cells examined, 1 cell was maximally sensitive to a frequency of 0.5 cycles per degree, 6 cells to 0.16 cycles per degree, 7 cells to 0.08 cycles per degree, and 2 cells to 0.04 cycles per degree. The receptive fields of $\mathrm{nBOR}$ cells preferring higher spatial frequencies $(0.16-$ 


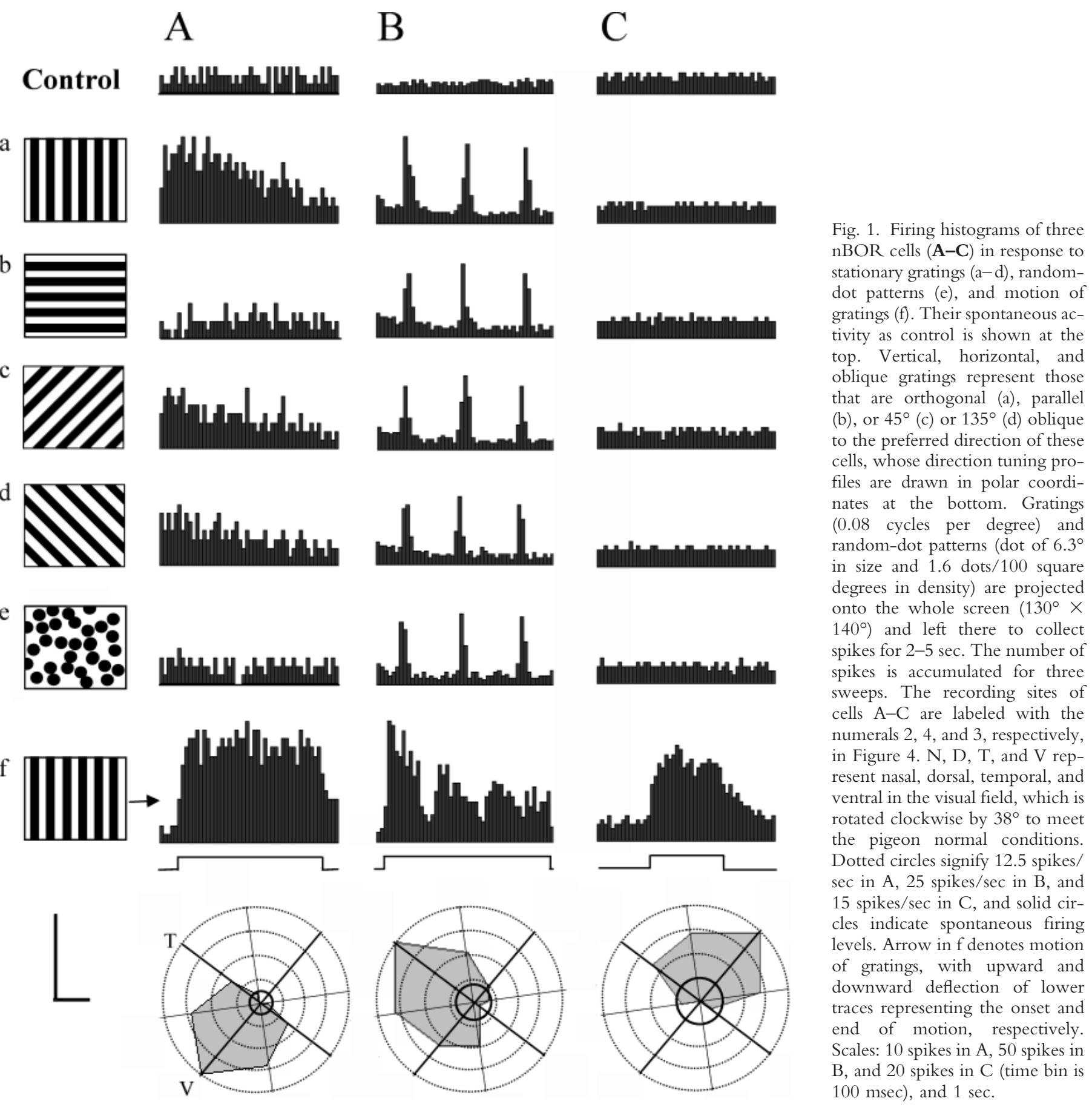

Fig. 1. Firing histograms of three cells $(\mathbf{A}-\mathbf{C})$ in response to dot patterns (e), and motion of gratings (f). Their spontaneous activity as control is shown at the top. Vertical, horizontal, and oblique gratings represent those that are orthogonal (a), parallel (b), or $45^{\circ}$ (c) or $135^{\circ}$ (d) oblique to the preferred direction of these whose direction tuning prothe bottom. Gratings (0.08 cycles per degree) and random-dot patterns (dot of $6.3^{\circ}$ tets 1100 square $140^{\circ}$ ) and left there to collect spikes for $2-5 \mathrm{sec}$. The number of spikes is accumulated for three sweeps. The recording sites of cells $\mathrm{A}-\mathrm{C}$ are labeled with the numerals 2,4 , and 3 , respectively, in Figure 4. N, D, T, and V represent nasal, dorsal, temporal, and ventral in the visual field, which is rotated clockwise by $38^{\circ}$ to meet normal conditions. sec in $A, 25$ spikes/sec in $B$, and 15 spikes/sec in C, and solid circles indicate spontaneous firing levels. Arrow in $\mathrm{f}$ denotes motion of gratings, with upward and downward deflection of lower traces representing the onset and nd of motion, respectively. $\mathrm{B}$, and 20 spikes in $\mathrm{C}$ (time bin is $100 \mathrm{msec}$ ), and $1 \mathrm{sec}$.

0.50 cycles per degree) were located in the central visual field, whereas those of cells sensitive to lower frequencies (0.04-0.08 cycles per degree) were located in the peripheral visual field. In the first group, all $\mathrm{nBOR}$ cells vigorously responded to motion of gratings or random-dot patterns. The relationship between firing rate produced by motion of gratings and that produced by stationary gratings in these cells is shown in Figure 2A and the cell distribution in Figure 2B.
The second group consisted of 5 cells $(7.4 \%)$ that were bursting in response to stationary stimuli (Fig. 1B). They produced OFF ( 3 cells) or no ( 2 cells) responses to changes in light. All of them were spontaneously active, with an average rate of $16.3 \pm 3.5$ spikes/sec. Gratings orthogonal to the preferred direction of these cells produced regular bursts, each of which lasted for $0.22 \pm 0.02$ $\sec (n=4 \times 5)$ and were intermittent for $1.37 \pm 0.06 \mathrm{sec}$ $(\mathrm{n}=3 \times 5)$. Firing rate in a burst reached $88.0 \pm 21.5$ 

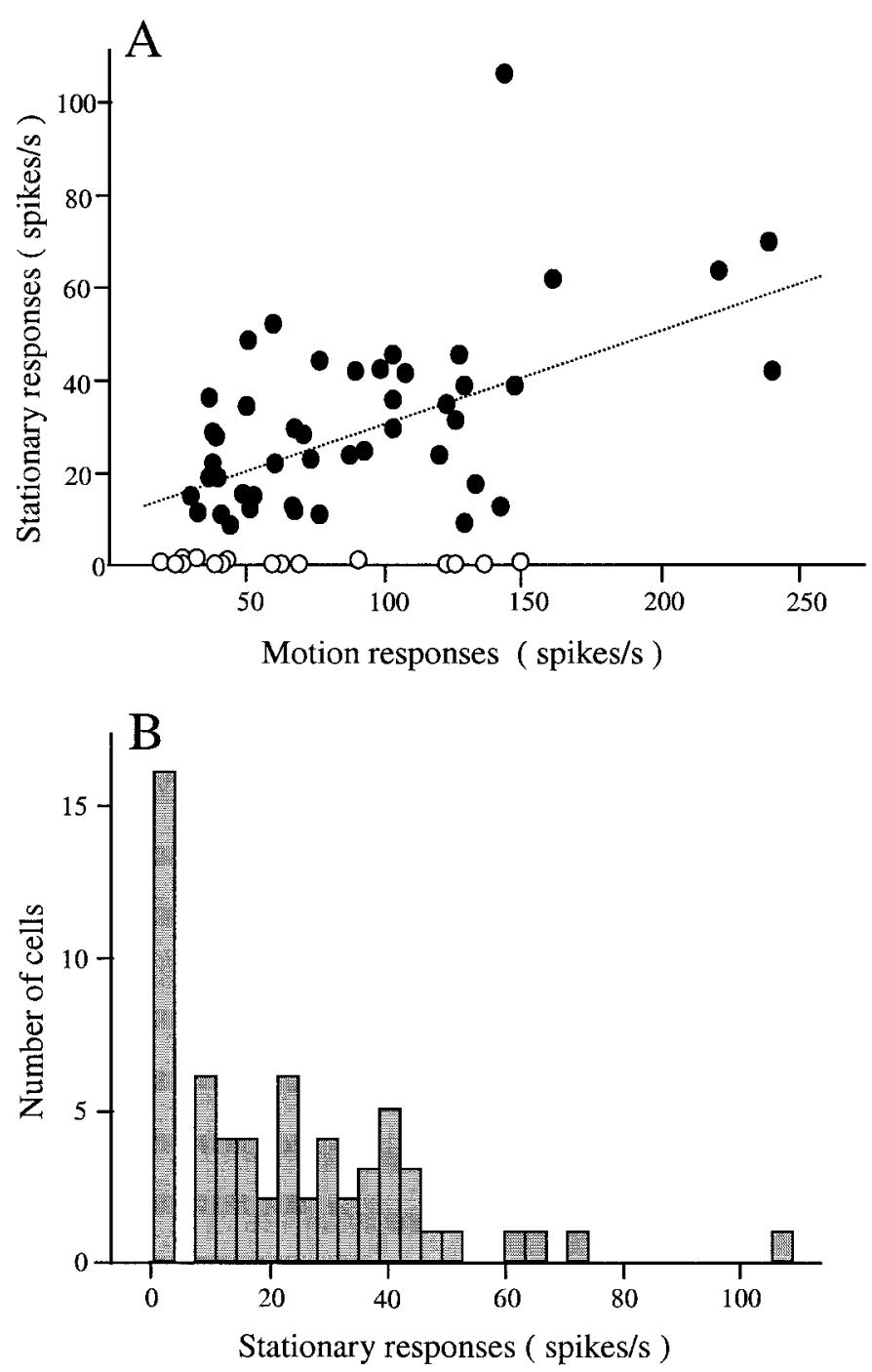

Fig. 2. A: Relationship between visual responses of $63 \mathrm{nBOR}$ cells to motion of gratings and those to stationary gratings. Firing rate in 47 cells (solid circles) produced by stationary gratings orthogonal to the preferred direction is positively correlated with that produced by gratings moved at the optimal velocity in the preferred direction. The dotted line corresponds to the linear regression with a slope of 0.24 . Sixteen cells (open circles) responded to motion but not to stationary patterns. B: Histograms showing the distribution of 63 cells plotted against the responses to the optimal stationary gratings (minus the spontaneous rate), clearly showing that the distribution is bimodal, corresponding to the two groups of cells.

spikes/sec ( $\mathrm{n}=4 \times 5)$, and that in an interburst was $17.6 \pm 3.0$ spikes $/ \mathrm{sec}(\mathrm{n}=3 \times 5)$. The interburst rate was not significantly different from the control value $(t=$ $1.342, \mathrm{n}=3 \times 5, P>0.01)$. This bursting activity could last for up to $300 \mathrm{sec}$ during stationary stimulation. Two of these cells were also examined for effects of gratings parallel or $45^{\circ}$ or $135^{\circ}$ oblique to the preferred direction on visual responsiveness. Their spontaneous rates were 20.9 and 20.0 spikes/sec, respectively. These orientational gratings always elicited regular bursts, each of which lasted for
$0.20-0.22 \mathrm{sec}$ in one cell and $0.20-0.24 \mathrm{sec}$ in the other, and interburst intervals were almost identical $(1.2-1.4 \mathrm{sec})$. For all orientations $\left(0^{\circ}, 45^{\circ}\right.$, and $\left.135^{\circ}\right)$, firing rate in bursts was 101-105 spikes/sec in one cell and 100-106 spikes/ $\mathrm{sec}$ in the other, and interburst rate was 22.0-22.3 and 20.0-20.8 spikes/sec, respectively. Firing parameters obtained with random-dot patterns were quite similar to those with orientational gratings. Motion of gratings orthogonal to the preferred direction elicited much stronger responses, though still in a bursting pattern; however, the burst duration was significantly prolonged (1.08-1.21 sec in one cell and 1.11-1.20 sec in the other) and the interburst duration shortened $(0.15-0.28 \mathrm{sec}$ and $0.11-0.30$ sec, respectively; Fig. 1B). The receptive fields of all bursting cells examined in the present study were located in the temporal region of the visual field.

The third group contained 16 cells $(23.5 \%)$ that were unresponsive to stationary stimuli (Fig. 1C). Five of them produced OFF responses, and 11 others did not respond to changes in light. This group included 11 spontaneous cells and 5 silent cells. Their average spontaneous rate was $19.6 \pm 12.2 \mathrm{spikes} / \mathrm{sec}$. Firing rate in response to gratings orthogonal to and parallel to the preferred direction of these cells was $20.2 \pm 11.5$ and $20.6 \pm 12.2$ spikes/sec, respectively. Statistical analysis showed that they did not respond to these gratings $\left(90^{\circ}: t=0.879 ; 0^{\circ}: t=0.928\right.$; $\mathrm{n}=11, P>0.01)$. Six of them were examined for visual responses to $45^{\circ}$ and $135^{\circ}$ oblique gratings. Their spontaneous rate was $17.4 \pm 9.0$ spikes $/ \mathrm{sec}$, and firing rate in response to $45^{\circ}$ and $135^{\circ}$ gratings was $17.5 \pm 11.2$ and $17.2 \pm 8.8$ spikes/sec, respectively. These data clearly showed that the cells' firing rate was kept at the spontaneous level. Stationary gratings with identical orientation but different frequencies (0.02-0.5 cycles per degree) or phases $\left(0^{\circ}, 180^{\circ}\right)$ did not elicit changes in visual responses. Stationary random-dot patterns did not produce visual responses either. However, motion of visual stimuli could evoke sustained responses from these cells (Fig. 1C). The relationship between firing rate produced by motion of gratings and that produced by stationary gratings in these cells is shown in Figure 2A and the cell distribution in Figure 2B. The omnidirectional cell recorded in the present study belonged to this group. It appeared that these visual responses were not correlated to the directional selectivity of nBOR cells. For example, 27 dorsoventralpreferring cells included 19 orientational cells, 2 bursting, cells and 6 motion-responsive cells, and 23 nasotemporalpreferring cells included 14 orientational, 3 bursting, and 6 motion-responsive cells.

Nine nBOR cells were examined for the functional actions of ERF and IRF in producing visual responses to stationary gratings. They had an average spontaneous rate of $20.6 \pm 15.1$ spikes/sec and responded to gratings in ERF that were orthogonal to the preferred direction with a firing rate of $39.3 \pm 22.8$ spikes/sec. It was obvious that the gratings in ERF significantly increased visual responsiveness $(t=3.581, \mathrm{n}=9, P<0.01)$. Gratings that were parallel to the preferred direction did not evoke visual responses. Motion of gratings produced vigorous responses 


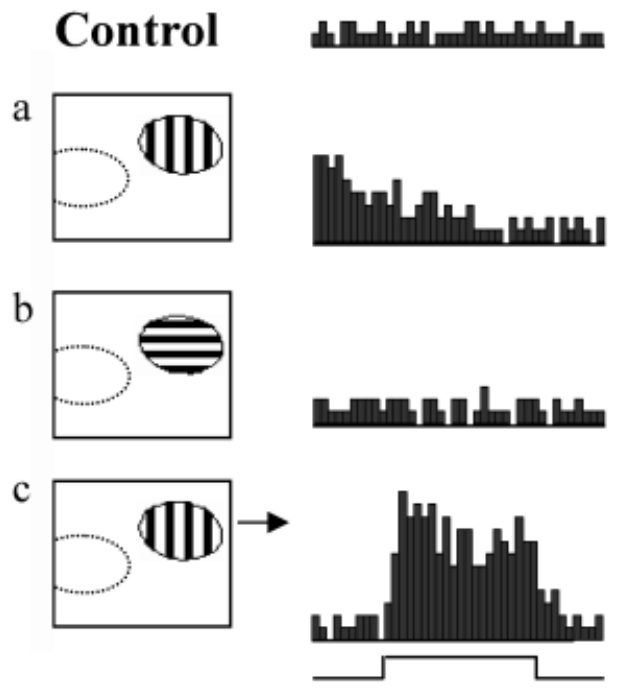

Fig. 3. Firing histograms showing differential roles of the excitatory receptive field (ERF) and inhibitory receptive field (IRF) of an $n B O R$ cell in its responses to gratings, which are presented in the display window restricted by ERF or IRF. Within ERF $\left(70^{\circ} \times 80^{\circ}\right)$, stationary gratings orthogonal to (a) but not those parallel to (b) the preferred direction of the cell produce visual responses. Within IRF $(70 \times 80$ deg), stationary gratings at any orientations $(\mathbf{d}, \mathbf{e})$ could not evoke visual

(Fig. 3a-c). On the other hand, these cells responded to stationary gratings within IRF that were orthogonal or parallel to the preferred direction with firing rates of $20.5 \pm 15.8$ and $20.7 \pm 18.4$ spikes/sec, respectively. It was clearly seen that both orientations could not change the firing activity of nBOR cells. However, motion of gratings within IRF in the direction opposite to the preferred direction could elicit significant inhibitory responses (Fig. 3d-f).

The recording sites of 30 cells, including 21 orientational, 4 bursting, and 5 motion-sensitive cells, were all marked within nBOR (Fig. 4), histologically verifying that our recording technique is very reliable. It appeared that visual properties of $\mathrm{nBOR}$ cells in response to stationary stimuli and motion might be not correlated with their locations within the nucleus. However, this conclusion might be a bias resulting from the small sample of $\mathrm{nBOR}$ cells used in the present study.

\section{DISCUSSION}

It has traditionally been thought that visual neurons in the avian $\mathrm{nBOR}$ are selective for the direction and velocity of motion of large-field stimuli and also respond in an inhibitory manner to motion in the direction opposite to the preferred direction. The present study shows for the first time that most $\mathrm{nBOR}$ neurons in pigeons respond to stationary stimuli, although their responses to motion are stronger than those to stationary stimuli. These visual responses to stationary stimuli could not be due to movements of the eyes, because eye movements were not observed to occur during the experiments. Otherwise, for example, the third group of nBOR cells should respond to

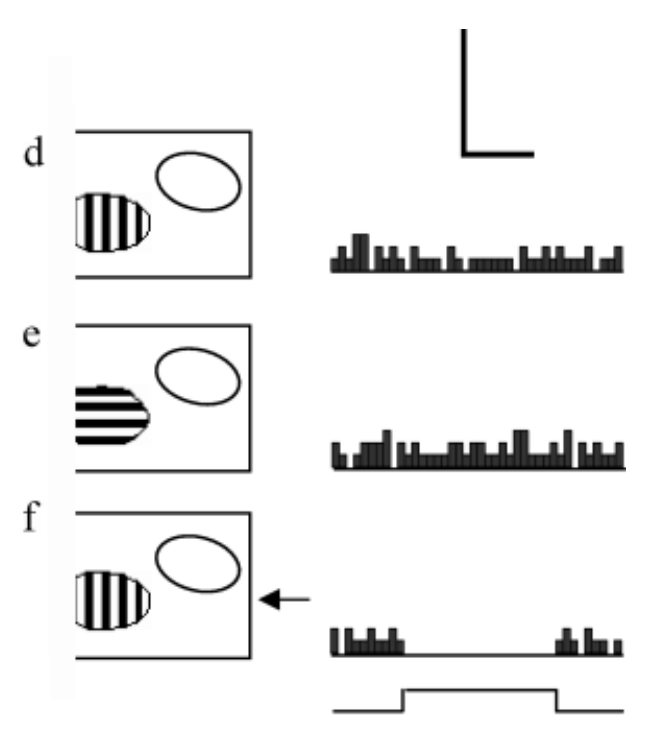

responses. Motion (rightward arrow) in $\operatorname{ERF}(\mathbf{c})$ in the preferred direction elicits responses, but motion (leftward arrow) in IRF in the direction opposite to the preferred direction induces inhibition (f). Upward and downward deflections of lower traces represent the onset and end of motion in $\mathrm{c}$ and $\mathrm{f}$. The recording site of the cell is labeled with the numeral 1 in Figure 4. Scales: 10 spikes (time bin is $100 \mathrm{msec}$ ) and $1 \mathrm{sec}$.

stationary gratings or random-dot patterns owing to motion of stimuli on the retina. The possibility could be excluded that visual responses of nBOR cells to stationary stimuli stem from $\mathrm{ON}$ responses probably caused by presenting visual patterns. In fact, most nBOR cells without ON-OFF responses to changes in light and most cells with OFF responses do produce visual responses to stationary stimuli.

The main finding of the present study is that there are three groups of cells in the pigeon $\mathrm{nBOR}$, which respond to stationary gratings and random-dot patterns in different ways. About $70 \%$ of cells are sensitive to the orientation of stripes in stationary gratings. Gratings orthogonal to the preferred direction for these cells produce strong responses, whereas stationary gratings parallel to the preferred direction and random-dot patterns without any orientational cues do not elicit visual responses at all. It is conceivable that obliquely oriented gratings could elicit medium-magnitude responses. This orientational sensitivity to stationary stimuli is similar to the sensitivity of optokinetic neurons to moving edges with orientation cues (Fu et al., 1998b; Wang et al., 2000b). The results indicate that $\mathrm{nBOR}$ cells could extract information on the orientation of a stimulus relative to its preferred direction of motion. A similar relationship between the preferred direction of motion and the optimal orientation of stimuli has also been reported for the visual cortex in mammals (Movshon et al., 1985; Scannell et al., 1996), showing that cortical cells could signal the direction of movement orthogonal to the preferred orientation. About $10 \%$ of cells discharge regular bursts in response to stationary gratings 
A
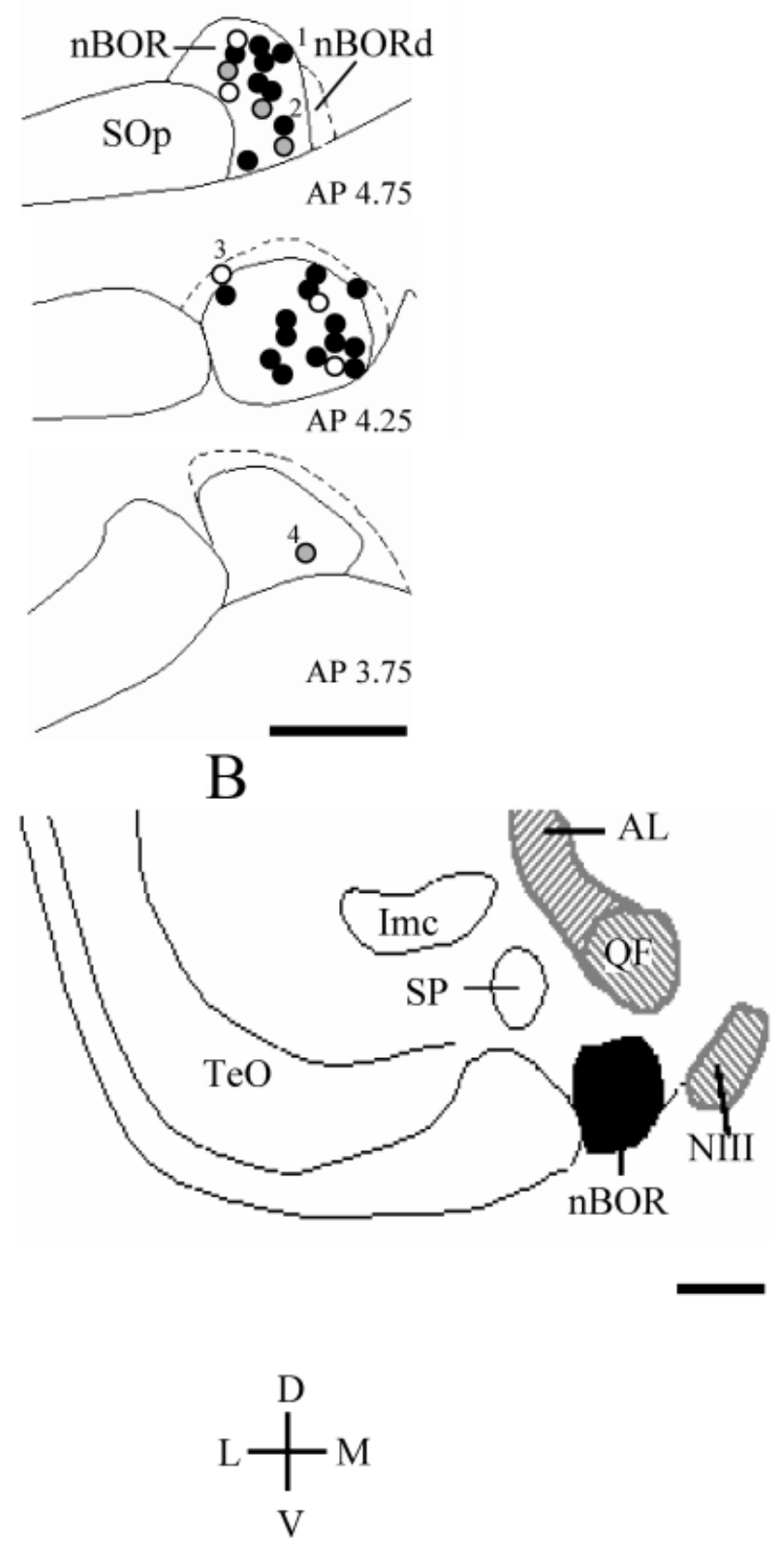

Fig. 4. Topographic distribution of 30 recording sites marked with dye (A) and anatomical location of the nBOR (B) in cross-sections of the pigeon's brain. Solid, stippled, and open circles represent orientational, bursting, and motion-sensitive cells, respectively. Sections in A are arranged rostrocaudalward from top to bottom. AP values symbolize the anterior-posterior levels in the pigeon brain atlas (Karten and Hodos, 1967). Numerals 1-4 label cells whose electrophysiological data are shown in other figures. D, L, V, and $\mathrm{M}$ represent dorsal, lateral, ventral, and medial sides. nBORd, nBOR dorsalis; SOp, stratum opticum; SP, nucleus subpretectalis; Imc, nucleus isthmi pars magnocellularis; AL, ansa lenticularis; QF, tractus quintofrontalis; NIII, nervus oculomotoris; $\mathrm{TeO}$, tectum opticum. Scale bars $=1 \mathrm{~mm}$. and random-dot patterns irrespective of the orientation of stimuli. It is interesting to note that some nBOR cells fire regular bursts in response to depolarizing current injections in brain slice preparations (Tang and Wang, unpublished data). This implies that this bursting activity may be endogenous to nBOR cells. Similar bursting activity has been found in the visual cortex (Gray and McCormick, 1996; Mancilla et al., 1998), in the pigeon tectum (Hardy et al., 1987; Luksch et al., 2001), and in the lateral geniculate nucleus (Weyand et al., 2001). These authors have suggested that bursting firing may be related to behavioral state (Weyand et al., 2001), and the switch between bursting and tonic modes can be controlled by modulatory afferents (Sherman, 2001), for example, from the pretectal nucleus lentiformis mesencephali (Nogueira and Britto, 1991; Wang et al., 2001) and from the visual forebrain (Britto et al., 1990). Because of the fact that detectability of signals is higher during bursting mode than during tonic mode, bursting firing may act as a "wake-up call" to report something changed in the environment (Sherman, 2001). This higher detectability would be essential for the function of the optokinetic system. Alternatively, these bursting cells may mediate synchronous firing in assemblies of neurons (Gray and McCormick, 1996), so that these assemblies of cells may work together in generating optokinetic nystagmus. The remaining $20 \%$ of cells examined in the present study respond to motion but not to stationary stimuli at any orientation. Although nBOR cells show distinct properties in response to stationary stimuli, all $\mathrm{nBOR}$ cells vigorously respond to motion of visual patterns. Under these circumstances, $\mathrm{nBOR}$ cells respond to motion in tonic firing mode, which could provide more faithful reconstruction of the visual world (Sherman, 2001).

The receptive field of visual neurons is a dynamic functional structure with spatiotemporal characteristics, depending on the general state of the brain (Wörgötter et al., 1998), local circuitry (Wang et al., 2000c), or visual environment. However, all the methods that the experimenters have used to date for mapping the receptive field of visual cells would confound time and space. This fault would probably not influence the results of the present study, because the size and separation or overlap of ERF and IRF are not essential factors influencing the visual responses of $\mathrm{nBOR}$ cells to stationary stimuli. The present study shows that ERF in most $\mathrm{nBOR}$ cells can detect not only visual patterns in motion but also stationary stimuli, whereas IRF can detect only motion in the direction opposite to the preferred direction. It appears that no spatial interaction exists between ERF and IRF in response to stationary gratings. However, the linear and nonlinear mechanisms underlying spatial summation of cortical cells in cats (Emerson et al., 1987; Reid et al., 1987; Ferster and Jagadeesh, 1991) may also act in the formation of receptive field properties of nBOR cells (Ibbotson et al., 1999).

Taken together with previous studies (Britto et al., 1981; Burns and Wallman, 1981; Morgan and Frost, 1981; Gioanni et al., 1984; Wylie and Frost, 1990; WolfOberhollenzer and Kirschfeld, 1994; Zhang et al., 1999), our study suggests that the almost all nBOR cells are selective for the direction and velocity of moving targets in 
generating optokinetic nystagmus. Meanwhile, most nBOR cells can detect stationary stimuli that are present before visual targets start to move or after the targets stop moving. This property might render $\mathrm{nBOR}$ cells ready to fire immediately at the moment when the targets start to move or resume moving. A small group of bursting cells can signal the appearance of targets in the visual field irrespective of their orientation and patterns, and a large group of cells report the appearance of targets with orientational cues. The fact that the firing rate of most $\mathrm{nBOR}$ cells in response to stationary patterns is diminished as a function of time may imply that these changes give some cues for stabilization of retinal images.

\section{ACKNOWLEDGMENTS}

We thank Dr. Yu-Xi Fu for writing the computer program that presents visual stimuli and performs online analysis of the data.

\section{REFERENCES}

Baldo MV, Britto LR. 1990. Accessory optic-pretectal interactions in the pigeon. Braz J Med Biol Res 23:1037-1040.

Britto LRG, Natal CL, Marcondes AM. 1981. The accessory optic system in pigeons: receptive field properties of identified neurons. Brain Res 206:149-154.

Britto LRG, Gasparotto OC, Hamassaki DE. 1990. Visual telencephalon modulates directional selectivity of accessory optic neurons in pigeons. Vis Neurosci 4:3-10.

Burns S, Wallman J. 1981. Relation of single unit properties to the oculomotor function of the nucleus of the basal optic root (AOS) in chickens. Exp Brain Res 42:171-180.

Diekamp B, Hellmann B, Troje NF, Wang SR, Güntürkün O. 2001. Electrophysiological and anatomical evidence for a direct projection from the nucleus of the basal optic root to the nucleus rotundus in pigeons. Neurosci Lett 305:103-106.

Emerson RC, Citron MC, Vaughn WJ, Klein SA. 1987. Nonlinear directionally selective subunits in complex cells of cat striate cortex. J Neurophysiol 58:33-65.

Erichsen JT, Hodos W, Evinger C, Bessette BB, Phillips SJ. 1989. Head orientation in pigeon: postral, locomotor and visual determinants. Brain Behav Evol 33:268-278.

Ferster D, Jagadeesh B. 1991. Nonlinearity of spatial summation in simple cells of areas 17 and 18 of cat visual cortex. J Neurophysiol 66:1667-1679.

Fite KV. 1985. Pretectal and accessory-optic visual nuclei of fish, amphibia and reptiles: theme and variations. Brain Behav Evol 26:71-90.

Frost BJ, Sun HJ. 1997. Visual motion processing for figure/ground segregation, collision avoidance, and optic flow analysis in the pigeon. In: Srinivasan MV, Venkatesh S, editors. From living eyes to seeing machines. New York: Oxford University Press. p 80-103.

Fu YX, Gao HF, Guo MW, Wang SR. 1998a. Receptive field properties of visual neurons in the avian nucleus lentiformis mesencephali. Exp Brain Res 118:279-285.

Fu YX, Xiao Q, Gao HF, Wang SR. 1998b. Stimulus features eliciting visual responses from neurons in the nucleus lentiformis mesencephali in pigeons. Vis Neurosci 15:1079-1087.

Gioanni H, Rey J, Villalobos J, Dalbera A. 1984. Single unit activity in the nucleus of the basal optic root (nBOR) during optokinetic, vestibular and visuo-vestibular stimulations in the alert pigeon (Columba livia). Exp Brain Res 57:49-60.

Gray CM, McCormick DA. 1996. Chattering cells: superficial pyramidal neurons contributing to the generation of synchronous oscillations in the visual cortex. Science 274:109-113.

Gu Y, Wang Y, Wang SR. 2001. Directional modulation of visual re- sponses of pretectal neurons by accessory optic neurons in pigeons. Neuroscience 104:153-159.

Hardy O, Audinat E, Jassik-Gerschenfeld D. 1987. Electrophysiological properties of neurons recorded intracellularly in slices of the pigeon optic tectum. Neuroscience 23:305-318.

Hellon RF. 1971. The marking of electrode tip positions in nervous tissue. J Physiol (London) 214:12.

Ibbotson MR, Clifford CW, Mark RF. 1999. A quadratic nonlinearity underlies direction selectivity in the nucleus of the optic tract. Vis Neurosci 16:991-1000.

Karten HJ, Hodos W. 1967. A stereotaxic atlas of the brain of the pigeon (Columba livia). Baltimore: Johns Hopkins Press.

Luksch H, Karten HJ, Kleinfeld D, Wessel R. 2001. Chattering and differential signal processing in identified motion-sensitive neurons of parallel visual pathways in the chick tectum. J Neurosci 21:6440-6446.

Mancilla JG, Fowler M, Ulinski PS. 1998. Responses of regular spiking and fast spiking cells in turtle visual cortex to light flashes. Vis Neurosci 15:979-993.

McKenna OC, Wallman J. 1985. Accessory optic system and pretectum of birds: comparisons with those of other vertebrates. Brain Behav Evol 26:91-116.

Morgan B, Frost BJ. 1981. Visual response properties of neurons in the nucleus of the basal optic root of pigeons. Exp Brain Res 42:184-188.

Movshon JA, Adelson EH, Gizzi MS, Newsome WT. 1985. The analysis of moving visual patterns. Exp Brain Res Suppl 11:117-151.

Mustari MJ, Fuchs AF. 1989. Response properties of single units in the lateral terminal nucleus of the accessory optic system in the behaving primate. J Neurophysiol 61:1207-1220.

Nogueira MI, Britto LR. 1991. Extraretinal modulation of accessory optic units in the pigeon. Braz J Med Biol Res 24:623-631.

Reid RC, Soodak RE, Shapley RM. 1987. Linear mechanisms of directional selectivity in simple cells of cat striate cortex. Proc Natl Acad Sci USA 84:8740-8744.

Scannell JW, Sengpiel F, Tovee MJ, Benson PJ, Blakemore C, Young MP. 1996. Visual motion processing in the anterior ectosylvian sulcus of the cat. J Neurophysiol 76:895-907.

Sherman SM. 2001. Tonic and burst firing: dual modes of thalamocortical relay. Trends Neurosci 24:122-126.

Soodak RE, Simpson JI. 1988. The accessory optic system of rabbit. I. Basic visual response properties. J Neurophysiol 60:2037-2054.

Wang Y, Gu Y, Wang SR. 2000a. Modulatory effects of the nucleus of the basal optic root on rotundal neurons in pigeons. Brain Behav Evol $56: 287-292$.

Wang Y, Gu Y, Wang SR. 2000b. Feature detection of visual neurons in the nucleus of the basal optic root in pigeons. Brain Res Bull 51:165-169.

Wang Y, Xiao J, Wang SR. 2000c. Excitatory and inhibitory receptive fields of tectal cells are differentially modulated by magnocellular and parvocellular divisions of the pigeon nucleus isthmi. J Comp Physiol A186:505-511.

Wang Y, Gu Y, Wang SR. 2001. Directional responses of basal optic neurons are modulated by the nucleus lentiformis mesencephali in pigeons. Neurosci Lett 311:33-36.

Weyand TG, Boudreaux M, Guido W. 2001. Burst and tonic response modes in thalamic neurons during sleep and wakefulness. J Neurophysiol 85:1107-1118.

Wolf-Oberhollenzer F, Kirschfeld K. 1994. Motion sensitivity in the nucleus of the basal optic root of the pigeon. J Neurophysiol 71:1559-1573.

Wörgötter F, Suder K, Zhao YQ, Kerscher N, Eysel UT, Funke K. 1998. State-dependent receptive field restructuring in the visual cortex. Nature 396:165-168.

Wylie DR, Frost BJ. 1990. Visual response properties of neurons in the nucleus of the basal optic root of the pigeon: a quantitative analysis. Exp Brain Res 82:327-336.

Zhang T, Fu YX, Hu J, Wang SR. 1999. Receptive field characteristics of neurons in the nucleus of the basal optic root in pigeons. Neuroscience 91:33-40. 